2008-02-08

\title{
Perceived barriers to organizational creativity
}

\author{
Mostafa, MM
}

http://hdl.handle.net/10026.1/8371

10.1108/13527600810848845

Cross Cultural Management: An International Journal

Emerald

All content in PEARL is protected by copyright law. Author manuscripts are made available in accordance with publisher policies. Please cite only the published version using the details provided on the item record or document. In the absence of an open licence (e.g. Creative Commons), permissions for further reuse of content should be sought from the publisher or author. 


\title{
Perceived barriers to organizational creativity A cross-cultural study of British and Egyptian future marketing managers
}

\author{
Mohamed M. Mostafa \\ Department of Business Administration, Gulf University for Science \\ and Technology, Hawally, Kuwait, and \\ Ahmed El-Masry \\ Plymouth Business School, University of Plymouth, Drake Circus, \\ Plymouth, UK
}

\begin{abstract}
Purpose - The overall purpose of this research is to further the understanding of how future marketing managers in Egypt and the UK perceive creativity barriers. The paper also examines the construct validity of the barriers to creativity scale in an Arab non-Western context.

Design/methodology/approach - A sample of 125 respondents was used to achieve the research purpose. Respondents completed a 17-item instrument designed to assess barriers to creativity in business organizations.

Findings - Discriminant analysis results showed that Egyptians differ from British with respect to their attitudes towards organizational creativity barriers. $t$-test procedure confirmed also that gender and age have significant effects on the attitudes towards creativity barriers.

Originality/value - This study has provided some insights into the factors associated with organizational creativity barriers in Egypt and the UK. The more is known of how future managers perceive creativity barriers, the more quickly and efficiently creativity can be stimulated.

Keywords Creative thinking, Attitudes, Marketing, Egypt, Cross-cultural studies, United Kingdom Paper type
\end{abstract}

\section{Introduction}

Creativity may be the most important tool in a manager's arsenal as it can lead to new and better solutions to business and customer problems. Thus creativity may be the key to market success and improved operating efficiencies (Herbig and Jacobs, 1996). Kao (1991, p. 14) suggests that creativity may be defined as "a human process leading to a result which is novel (new), useful (solves an existing problem or satisfies an existing need), and understandable (can be reproduced)". However, the term creativity, used in a workplace context, has many definitions and interpretations. Researchers, instructors, and consultants often explain it by referring to one or more of a variety of factors, including attributes, conceptual skills, behaviours, abilities, technologies, empowerment, the process of experience, or external influences. This lack of consensus is really not surprising; perhaps attempts to reach consensus are at odds with the very notion of creativity. However, if organisations want to encourage creativity, they must explore the range of blockages to creativity. This will permit managers to focus on the manifestations of creativity they believe are appropriate to their specific problems or situations (Gundry and Kickul, 1994).

Although there have been several studies concerning the issue of creativity and innovation, few authors have attempted to study creativity cross-culturally. In most

\footnotetext{
Cross Cultural Management: An International Journal Vol. 15 No. 1, 2008 pp. $81-93$

Emerald Group Publishing Limited 1352-7606 DOI $10.1108 / 13527600810848845$
} 
$\mathrm{CCM}$

15,1

82 previous research on organizational creativity, there has been a bias toward factors that appear to enhance creativity; there is comparatively little research evidence on factors that may undermine creativity. In this research, we aim to fill these research gaps by examining attitudes towards organizational barriers to creativity in Egypt and the UK. Determining such attitudes is critical since it has been found that virtually all of the most important barriers to effective management are related to organizational members' attitudes and behaviours concerning creativity and creative change (Basadur et al., 1988).

This paper is organised as follows. First the "research objectives" are presented. Secondly the "literature review and hypotheses development" reviews the relevant literature and develops the research hypotheses. The section "methodology" deals with the research methodology. The "results" appear next and finally "research implications, limitations and directions for future research" are dealt.

\section{Research objectives}

The main objective of this research is to investigate the Egyptian and the UK future marketing managers' perceptions of the factors negatively affecting organizational creativity. Specifically, we aim to:

- test how future marketing managers in Egypt and the UK differ in their perceived attitudes towards creativity barriers;

- analyze the impact of some demographic variables such as sex and age on the attitudes towards creativity barriers in Egypt and the UK; and

- test the validity and reliability of the recently developed barriers to creativity (BTC) instrument. This study represents the first applications of the scale crossculturally and, hence, the reliability and convergent validity of the instrument will be examined.

The overall purpose of this research is to further our understanding of how respondents in Egypt and the UK perceive creativity and innovativeness. The more we know of how managers perceive barriers to creativity, the more quickly and efficiently creativity can be stimulated, thereby allowing other global players to capitalize on opportunities for innovation and partnering that will emerge in the future.

\section{Literature review and hypotheses development}

A large body of literature has focused on determining a set of personal characteristics and attributes associated with creative achievement (Barron and Harrington, 1981; Davis, 1989; Martindale, 1989). This research has examined personal characteristics ranging from biographical factors to measures of cognitive styles and intelligence (Amabile, 1983; Barron and Harrington, 1981; Davis, 1989; Hocevar and Bachelor, 1989; Woodman and Schoenfeldt, 1989). In general, these studies have demonstrated that a stable set of core personal characteristics, including broad interests, attraction to complexity, intuition, aesthetic sensitivity, toleration of ambiguity, self confidence, relate positively and consistently to measures of creative performance across a variety of domains.

Prior research also examined organisational factors, such as job complexity and supervision style that facilitate creative performance (e.g. Amabile, 1988; Amabile et al., 1996). Mott's (1972) comparative research showed that effective organizations are simultaneously efficient and creative. Efficiency means optimising, stabilizing, and 
polishing current methods and routines for highest quantity, quality, and customer satisfaction at the lowest cost possible. Organisational creativity means deliberately changing current methods to make new levels of quantity, quality, cost, and customer satisfaction possible. Both new methods and new products result from creativity.

Basadur et al. (2002) found that creativity can be developed, increased, and managed by organisations. Specific results from increasing organisational creativity can be identified, including new products and methods, increased efficiency, greater motivation, job satisfaction, teamwork, a focus on customer satisfaction, and more strategic thinking at all levels.

In an Arab context, a study by Makhamerah and Al-Dahhan (1988) examined factors affecting employees' innovation in public companies in Jordan. It concluded that innovation is affected by managerial attitudes, the establishment of objective criteria and encouragement of employees' interactions and exchange of ideas. Another study by Abu-Faris (1990) attempted to test the impact of certain factors on employees' innovation in a sample of public enterprises in Jordan. It found that material and nonmaterial incentives affected positively employees' innovation. It also found no impact of sex and position on employees' innovation.

Awamleh (1994) examined the relationship between managerial creativity (dependent variable) and sex, age, education, organisational level, and length of service as independent variables in a sample of 293 managers in Jordan. The study found that the most significant obstacles to creativity are those related to organisational climate.

Mikdashi (1999) assessed the effects of organisational climate on managers' creativity in Lebanon. This study also investigated the constitutive meaning of creativity as a construct through the relation between creativity and other organisational constructs.

Al-Beraidi and Rickards (2003) studied the creative team climate in Saudi Arabia. This study argued that creative performance of teams could be stimulated by leadership intervention. A transformational leadership style has been found the most appropriate in encouraging innovative behaviours.

Abu-Taieh (2003) studied the relationship between leadership style and individual innovative behaviour. A sample of 430 managers from five large industrial firms in Jordan participated in the study. A statistically significant relationship between leadership power and individual innovative behaviour was found. However, no statistically significant relationship between legitimate and reward power, on one hand, and individual innovative behaviour on the other hand was found.

Using a sample of 170 managers, Mostafa (2005) studied factors affecting organisational creativity in Egyptian organisations. The study detected a statistically significant difference in attitudes towards organisational creativity based on the managers' functional area in the organisation. The study also found that the higher the education of the manager, the more he or she is likely to adopt creative and innovative activities. The study detected no generation gap in the managers' attitudes towards organisational creativity. Finally, the study found that male managers have significantly favourable attitudes towards creativity compared with their female counterparts.

There is evidence that culture may affect one's attitudes towards creativity and innovativeness. Csikszentmihayli (1996) asserts that creativity is the cultural counterpart of genetic change resulting from biological evolution. In biological evolution random variations take place in genes and chromosomes, whereas in cultural evolution changes take place in memes, i.e. in units of information created, maintained and transmitted by the culture. Thus, creativity understood as a mental process cannot
Perceived barriers to organizational creativity 
$\mathrm{CCM}$

15,1

84

be isolated from the socio-cultural systems in which the individual functions (Rudowicz, 2003). Amabile et al. (1996) noted that creativity requires curiosity and risk taking. These are comfortable traits for most Westerners but not for the typical Arab. Most Arabs prefer the comfort of proven ideas and shy away from exploring risky options. They seem to prefer a more structured, team-oriented approach to avoid losing face or being excluded. According to Barakat (1993), the traditional culture, which is the dominant one in the Arab World, is characterised by the following facets: fatalism strengthened by conventional religious though; shame as apposed to guilt, reflected in the psychological drive to escape or prevent negative judgment by others rather than conscious questioning; conformity as apposed to creativity, which legitimises the status quo.

Gender is important in studying organisational creativity since creativity requires many behaviour patterns in which men and women differ. For example, Instone et al. (1983) found that men and women use different influence strategies in business activities and showed that men and women have different norms about how rewards should be used to influence creative organisational behaviour. The importance of examining creativity in relation to gender is based primarily on the socio-cultural differences among females and males (Abra, 1991). Traditionally, females in Western societies have been encouraged to conform, whereas males are expected to be active and dominant risk-takers (Block, 1976). Furthermore, Davis and Rimm (1989) acknowledge that most boys are provided with toys that enhance their visual-spatial abilities, such as trucks, and models, while Lever (1976) notes that the games of girls are often highly structured requiring turn-taking and rules. In addition, social expectations, conformity pressures and attitudes towards women in Arab countries may create "cultural blocks" to female creativity (Mostafa, 2003).

Previous research found that younger and less experienced managers are more likely to pursue creative strategies since older mangers dislike change from the status quo and show greater adherence to the norms of the organization (Hambrick and Mason, 1984). Work experience also gives individuals credibility as champions (Howell and Higgins, 1991) and makes them better able to navigate political coalitions in the organization (Chakrabarti, 1974). The review presented above suggests the following hypotheses:

H1. Respondents from Egypt and the UK will report statistically significant differences in attitudes towards creativity barriers as measured by the BTC scale.

H2. Male respondents will report higher discomfort towards creativity barriers, as measured by high levels on the BTC scale, compared to female respondents.

H3. Younger respondents will report higher dissatisfaction with organisational creativity barriers compared to older respondents.

\section{Methodology}

\section{Sample}

Collecting data by mail surveys in the Arab world has been very difficult (Nasif et al., 1991). In order to ensure an acceptable number of responses, a convenient sample was used. A network of contacts at universities throughout Egypt cooperated in distributing and returning the questionnaire. All of the contacts were university professors or 
administrators. Each contact received a packet containing between 10 and 20 questionnaires, depending on the number of students with whom they interacted. The questionnaires were administered to groups of post-graduate marketing students who completed them in the classroom. Students responded voluntarily and were not compensated for their participation. A total of 67 questionnaires were distributed. Seven questionnaires were excluded because respondents failed to complete the questionnaires properly. A total of 60 questionnaires from Egypt were coded and analysed. Seventy questionnaires were distributed by Ahmed El-Masry to a group of MBA students attending a Marketing Research class at the University of Manchester. A total of 65 usable questionnaires were coded and analysed for the UK portion of the research. There were no significant demographic differences found between the survey responses received from the UK and Egypt. The average age in the whole sample was 32.7 $(\mathrm{SD}=6.05)$. Females represented 63 per cent of the total sample.

\section{Instrument}

The questions for barriers to organizational creativity were taken from Wong and Pang (2003) research instrument. The 17-item BTC instrument (Appendix) was developed to assess barriers to creativity in Hong Kong organizations. The instrument has been previously found to be valid and reliable measure of organizational barriers to creativity when administered in Egypt (Mostafa, 2005).

\section{Procedure}

The Arabic version of the instrument administered in Egypt was created through careful translation and back-translation techniques (McGorr, 2000). First, the authors translated the instrument into Arabic. Then, these Arabic items were back-translated into English by a bilingual expert to make sure that the original content was kept in translation to decrease discrepancies between the English and Arabic measurements. No individual items were problematic in translation. In translating the instrument's items into Arabic, the authors followed Malinowski's (1935) technique of translation, which involves four steps:

(1) an inter linear, or word-by-word, translation;

(2) a "free" translation in which clarifying terms, conjunctions, etc. are added and word reinterpreted;

(3) an analysis and collation of the two translations, leading to; and

(4) a contextual specification of meaning.

However, it should be admitted that complete semantic equivalence in cross-cultural studies is a statistical fiction (Phillips, 1959).

\section{Results}

\section{Validity and reliability}

The barriers-to-organizational creativity scale was factor-analyzed by principal component analysis. In factor analysis, a rotation procedure is commonly applied which maximize the correlations of each item on a factor (Comrey and Lee, 1991). The organizational creativity construct comprises many interrelated items and, therefore, oblique rotation was applied as the rotation procedure. Advocates of oblique rotation assert that in the real world important factors are likely to be correlated; thus searching for unrelated factors is unrealistic (Dixon, 1993). Four factors were extracted in the
Perceived barriers to organizational creativity

85 
$\mathrm{CCM}$

15,1

86 analysis using a standard eigenvalue of 1.0 (Child, 1990) and an inspection of a scree plot.

Total variance explained (66.534 per cent) by these four components exceeds the 60 per cent threshold commonly used in social sciences to establish satisfaction with the solution (Hair et al., 1995). Factor one explained 40.465 per cent of the total variation with an eigenvalue of 6.879. Factor two explained 10.650 per cent of the total variation with an eigenvalue of 1.811, while factor three explained 8.582 per cent of the total variation with an eigenvalue of 1.459 . Factor four explained 6.837 per cent of the total variation with an eigenvalue of 1.162 . All of the item loadings for each factor were above 0.50, which is indicative of convergent validity (Hair et al., 1995). Factor one was labeled low commitment to organization and included items like "not feeling involved". Factor two was labeled lack of management support and included items like "no recognition and appreciation of work done". Factor three was labeled risk aversion and included items like "fear of failure". Factor four was labeled time and work pressure and included items like "time pressure".

The Kaiser-Mayer-Olkin (KMO) measure of sampling adequacy (Kaiser, 1970) was used to measure the adequacy of the sample for extraction of the four factors. The KMO value found (0.78) is indicative of a data set considered to be highly desirable for factor analysis (Kim and Mueller, 1978). The Bartlett's test of sphericity was used to test the multivariate normality of the set of distributions. This procedure also tests whether the correlation matrix is an identity matrix (factor analysis would be meaningless with an identity matrix). A significance value of $p<0.05$ indicates that the data do not produce an identity matrix or differ significantly from identity (George and Mallery, 2000). The analysis focusing on the sphericity of the distribution (Bartlett's sphericity test) allowed us to reject the hypothesis according to which the matrix would be unitary (approx. Chisquare $=2607.215, \mathrm{df}=136, p<0.001)$. This result implies that the data are thus approximately multivariate normal and acceptable for factor analysis.

Scores on each of the four factors were calculated and saved for each respondent in the sample. These would be used as independent variables for discriminant analysis. The decision to use the factor scored, saved by SPSS was based on our intention to maintain as much of the information from the original 17 -item scale as possible. Brodowsky and Anderson (2000) used a similar procedure in a cross-cultural study of consumers' attitudes towards time.

Using SPSS version 13.0, an internal consistency analysis was performed to assess the reliability aspect of the BTC instrument. Reliability refers to the instrument's ability to provide consistent results in repeated uses (Gatewood and Field, 1990). Coefficient (Cronbach's) alpha is the basic measure for reliability (Green et al., 2000). The 17-item instrument had an acceptable coefficient alpha $(\alpha=0.895)$. Nunnally (1978) suggested that an alpha value of 0.7 is acceptable. The alpha value found for the scale indicated, therefore, that it is a sufficiently reliable measure of organizational creativity barriers.

An examination of the item-to-total correlations revealed two items that detract from the scale (items 11 and 16). When the two items were deleted from the scale, alpha level reached 0.911and the corrected item-total correlations ranged from 0.32 to 0.79 as shown in Table I. Further examination of item statistics identified no items that suppress the alpha level.

Based on the statistical analyses, the BTC instrument appears to be a fairly valid and reliable measure of barriers to organizational creativity. 


\begin{tabular}{|c|c|c|c|}
\hline & Corrected item-total correlation & Cronbach's alpha if item deleted & \\
\hline Q1 & 0.761 & 0.900 & organizational \\
\hline Q2 & 0.639 & 0.905 & \\
\hline Q3 & 0.644 & 0.904 & creativity \\
\hline Q4 & 0.752 & 0.901 & \\
\hline Q5 & 0.628 & 0.905 & \\
\hline Q6 & 0.789 & 0.899 & 87 \\
\hline Q7 & 0.385 & 0.912 & \\
\hline Q8 & 0.554 & 0.904 & \\
\hline Q9 & 0.515 & 0.909 & \\
\hline Q10 & 0.760 & 0.900 & \\
\hline Q12 & 0.688 & 0.903 & \\
\hline Q13 & 0.686 & 0.903 & \\
\hline Q14 & 0.350 & 0.913 & \\
\hline Q15 & 0.325 & 0.914 & Table I. \\
\hline Q17 & 0.562 & 0.907 & Item-total statistics \\
\hline
\end{tabular}

\section{Discriminant analysis}

To test H1, a two-group discriminant analysis was used to explore how and if Egyptian and British respondents differ with respect to their attitudes towards organizational creativity barriers. Discriminant analysis was used because this method determines the ability of the criterion variable to discriminate between the two groups of respondents. The four dimensions of the organizational creativity barriers, represented by scores on each of the factors extracted through principal components analysis were used as independent variables. Stepwise discriminant analysis was used for entering independent variables one at a time on the basis of their discriminating power. The results are presented in Table II.

A single discriminant function, with eigenvalue of 0.636 was significant at $p<0.001$. The value of Wilks' Lambda was 0.611 with $\chi^{2}$ value of 59.317 . This statistic is formed as the ratio of within-groups sums of squares and total sums of squares and represents the proportion of variance in the discriminant scores not explainable by between-group differences. Smaller values for Wilks' Lambda represent greater cross-group differences and smaller within-group differences (Klecka, 1987). This particular value indicates moderate to large differences between Egyptian and British respondents' attitudes towards organizational creativity barriers as measured by the discriminant function. Examination of group centroids suggests that the groups do differ with

\begin{tabular}{|c|c|c|c|c|}
\hline Independent variables & $\begin{array}{l}\text { Egypt group } \\
\text { means }\end{array}$ & $\begin{array}{l}\text { UK group } \\
\text { means }\end{array}$ & $\begin{array}{l}\text { Standardized canonical } \\
\text { discriminant coefficients }\end{array}$ & \multirow{7}{*}{$\begin{array}{r}\text { Table II. } \\
\text { Results of discriminant } \\
\text { analysis }\end{array}$} \\
\hline \multirow{6}{*}{$\begin{array}{l}\text { Factor } 1 \\
\text { Factor } 2 \\
\text { Factor } 3 \\
\text { Factor } 4 \\
\text { Overall significance } \\
\text { discriminant function } \\
\text { Group centroids }\end{array}$} & -0.6378 & 0.5887 & 0.945 & \\
\hline & -0.2459 & 0.2270 & 0.077 & \\
\hline & -0.1839 & 0.1697 & 0.093 & \\
\hline & -0.1677 & -0.1548 & -0.176 & \\
\hline & Wilks' $\lambda=0.611$ & $\chi^{2}=59.317$ & \multirow{2}{*}{ Canonical correlation $=0.624$} & \\
\hline & Egyptian -0.823 & British 0.760 & & \\
\hline
\end{tabular}


$\mathrm{CCM}$

15,1

\section{8}

respect to the discriminant function. The value for Egyptian respondents was -0.823 while for British respondents the group centroid was 0.760 .

Table III illustrates the discriminant function's ability to correctly classify Egyptian and British survey respondents based on their attitudes towards organizational creativity barriers. Of the 125 individuals included in the analysis, 60 (48 per cent) were Egyptians and the remaining 65 (52 per cent) were British. The table illustrates that the discriminant function correctly classified 44 of the Egyptian respondents (73.3 per cent) as Egyptians, and 59 of the British respondents (90.8) as British. Overall, the discriminant function correctly classified 82.4 per cent of the sample. Since it has been suggested that the classification accuracy achieved by discriminant analysis should be approximately 25 per cent greater than that obtained by chance (Malhotra, 2004), the model seems to have satisfactory predictive power. That is, knowing an individual's scores on the independent variables (which are linear combination of the original items in the scale) enables the researcher to correctly predict nationality (Egyptian or British) of the survey 82 per cent of the time. Thus, it appears that Egyptians differ from British with respect to their attitudes towards organizational creativity. These results provide strong support for the first hypothesis, which states "respondents from Egypt and the UK will report statistically significant differences in attitudes towards creativity barriers as measured by the BTC scale."

\section{Gender differences hypothesis}

$t$-tests (Table IV) show that male respondents have generally reported higher discomfort towards creativity barriers, as measured by high levels on the BTC scale, compared to female respondents. In seven scale statements the differences were statistically significant. This result provides partial support for the second hypothesis. Such an outcome reflects cultural characteristics that encourage females to conform, whereas males are expected to be active and dominant risk-takers. It is plausible that the gender differences in attitudes towards organisational creativity are determined, in part, by different identifications of the gender roles.

\section{Age hypothesis}

Using the $t$-test procedure (Table V), it was found that the mean scores for younger and older managers are statistically significant. In virtually all the scale statements younger respondents reported higher dissatisfaction with organisational creativity barriers compared to older respondents. Hence, $H 3$ is supported. This result corroborates previous research conducted in the West (e.g. Hambrick and Mason, 1984), which generally shows that older mangers dislike change from the

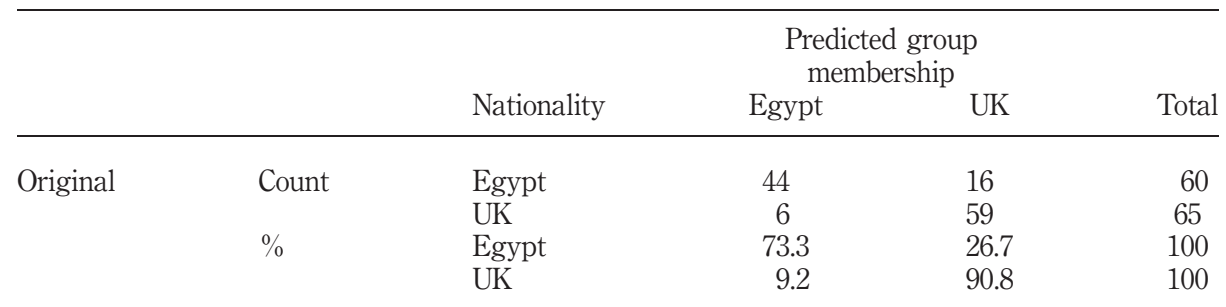

Table III.

Classification results 


\begin{tabular}{|c|c|c|c|c|c|c|c|c|}
\hline & Sex & $N$ & Mean & S.D. & $t$ & $\mathrm{df}$ & Significance & Perceived \\
\hline \multirow[t]{2}{*}{ Q1 } & Male & 46 & 3.4773 & 1.1555 & 3.713 & 123 & 0.000 & nizational \\
\hline & Female & 79 & 2.8860 & 1.3420 & & & & organizational \\
\hline \multirow[t]{2}{*}{ Q2 } & Male & 46 & 3.6970 & 1.0624 & 6.559 & 123 & 0.000 & creativity \\
\hline & Female & 79 & 2.8509 & 0.9429 & & & & \\
\hline \multirow{2}{*}{ Q3 } & Male & 46 & 3.3712 & 1.2257 & 1.272 & 123 & 0.204 & \\
\hline & Female & 79 & 3.1754 & 1.1768 & & & & 9 \\
\hline \multirow[t]{2}{*}{ Q4 } & Male & 46 & 3.1439 & 1.0851 & 3.010 & 123 & 0.003 & \\
\hline & Female & 79 & 2.7281 & 1.0749 & & & & \\
\hline \multirow[t]{2}{*}{ Q5 } & Male & 46 & 3.4318 & 1.1734 & 2.675 & 123 & 0.008 & \\
\hline & Female & 79 & 3.0088 & 1.2068 & & & & \\
\hline \multirow[t]{2}{*}{ Q6 } & Male & 46 & 3.4015 & 1.1247 & 2.684 & 123 & 0.008 & \\
\hline & Female & 79 & 2.9912 & 1.2722 & & & & \\
\hline \multirow[t]{2}{*}{ Q7 } & Male & 46 & 3.3158 & 0.9689 & 1.141 & 123 & 0.225 & \\
\hline & Female & 79 & 3.1582 & 0.9714 & & & & \\
\hline \multirow[t]{2}{*}{ Q8 } & Male & 46 & 3.4386 & 0.9951 & 3.740 & 123 & 0.000 & \\
\hline & Female & 79 & 2.9015 & 1.2553 & & & & \\
\hline \multirow[t]{2}{*}{ Q9 } & Male & 46 & 3.4123 & 0.9101 & 2.181 & 123 & 0.030 & \\
\hline & Female & 79 & 3.1061 & 1.2816 & & & & \\
\hline \multirow[t]{2}{*}{ Q10 } & Male & 46 & 3.1842 & 1.1947 & 0.063 & 123 & 0.950 & \\
\hline & Female & 79 & 3.1742 & 1.3005 & & & & \\
\hline \multirow[t]{2}{*}{ Q12 } & Male & 46 & 3.3788 & 1.0376 & 1.726 & 123 & 0.086 & \\
\hline & Female & 79 & 3.1316 & 1.2084 & & & & \\
\hline \multirow[t]{2}{*}{ Q13 } & Male & 46 & 3.3864 & 1.0817 & -0.063 & 123 & 0.950 & \\
\hline & Female & 79 & 3.3947 & 0.9751 & & & & \\
\hline \multirow[t]{2}{*}{ Q14 } & Male & 46 & 3.3258 & 1.1085 & 0.010 & 123 & 0.992 & \\
\hline & Female & 79 & 3.3246 & 0.8146 & & & & Table IV. \\
\hline \multirow[t]{2}{*}{ Q15 } & Male & 46 & 3.4621 & 0.9838 & -0.932 & 123 & 0.352 & $t$-tests for sex differences \\
\hline & Female & 79 & 3.5702 & 0.8089 & & & & in attitudes towards \\
\hline \multirow[t]{2}{*}{ Q17 } & Male & 46 & 3.0530 & 0.9189 & -0.951 & 123 & 0.342 & organizational creativity \\
\hline & Female & 79 & 3.1842 & 1.2378 & & & & barriers \\
\hline
\end{tabular}

status quo and show greater adherence to the norms of the organization unlike younger and less experienced managers who are more likely to pursuer creative strategies.

\section{Implications, limitations and future research}

The results of this research have far-reaching implications. The managers focusing on the creative talent of human resources of their organisations will find this study interesting, informative, and relevant. The root causes of perceived barriers to creativity are very important. We believe that the removal of such barriers will result in greater utilisation of creative talents in organisations.

In contrast to Western individualistic culture, the Egyptians are an extremely collectivistic people (Hofstede, 1980) and there is ease in social interactions and formation of groups. This collectivism can result in strong group loyalty and cohesiveness (Ali, 1993) and is a potential source of beneficial "social capital" the resources derived from the network of relationship in a workgroup or organisation (Napahiet and Ghoshal, 1998). Egyptians value the person and the relationship more than the task. The challenge for an Egyptian work team, then, is maintaining a focus on powerful influence on group performance. While this can be positive, it can simultaneously limit the group's openness to alternative 


\begin{tabular}{|c|c|c|c|c|c|c|c|c|}
\hline \multirow{5}{*}{$\begin{array}{l}\text { CCM } \\
15,1\end{array}$} & & Age & $N$ & Mean & $\mathrm{SD}$ & $t$ & $\mathrm{df}$ & Significance \\
\hline & $\mathrm{Q} 1$ & $\leq 25$ & 53 & 3.9327 & 0.8506 & 8.772 & 123 & 0.000 \\
\hline & & $>26$ & 72 & 2.6690 & 1.2756 & & & \\
\hline & Q2 & $\leq 25$ & 53 & 3.6827 & 0.99771 & 4.853 & 123 & 0.000 \\
\hline & & $>26$ & 72 & 3.0282 & 0.0781 & & & \\
\hline \multirow{20}{*}{90} & Q3 & $\leq 25$ & 53 & 3.9808 & 1.0142 & 8.981 & 123 & 0.000 \\
\hline & & $>26$ & 72 & 2.7676 & 1.0696 & & & \\
\hline & Q4 & $\begin{array}{l}\leq 25 \\
>26\end{array}$ & $\begin{array}{l}53 \\
72\end{array}$ & $\begin{array}{l}3.4712 \\
25704\end{array}$ & $\begin{array}{l}0.9026 \\
1.0745\end{array}$ & 6.940 & 123 & 0.000 \\
\hline & Q5 & $\leq 25$ & 53 & $\begin{array}{l}2.5 / 44 \\
3.9808\end{array}$ & $\begin{array}{l}1.0145 \\
0.8587\end{array}$ & 9.264 & 123 & 0.000 \\
\hline & & $>26$ & 72 & 2.6901 & 1.2156 & & & \\
\hline & Q6 & $\leq 25$ & 53 & 3.8365 & 0.9254 & 7.716 & 123 & 0.000 \\
\hline & & $>26$ & 72 & 2.7535 & 1.1920 & & & \\
\hline & Q7 & $\leq 25$ & 53 & 3.5865 & 0.9913 & 5.026 & 123 & 0.000 \\
\hline & & $>26$ & 72 & 3.9859 & 0.8750 & & & \\
\hline & Q8 & $\leq 25$ & 53 & 3.6731 & 1.2183 & 6.594 & 123 & 0.000 \\
\hline & & $>26$ & 72 & 2.7676 & 0.9352 & & & \\
\hline & Q9 & $\leq 25$ & 53 & 3.6538 & 0.9113 & 5.177 & 123 & 0.000 \\
\hline & & $>26$ & 72 & 2.9507 & 1.1443 & & & \\
\hline & Q10 & $\leq 25$ & 53 & 3.7115 & 1.1879 & 6.176 & 123 & 0.000 \\
\hline & & $>26$ & 72 & 2.7887 & 1.1350 & & & \\
\hline & Q12 & $\leq 25$ & 53 & 3.7212 & 0.9186 & 5.807 & 123 & 0.000 \\
\hline & & $>26$ & 72 & 2.9296 & 1.1463 & & & \\
\hline & Q13 & $\leq 25$ & 53 & 3.9038 & 0.8535 & 7.378 & 123 & 0.000 \\
\hline & & $>26$ & 72 & 3.0141 & 0.9892 & & & \\
\hline & Q14 & $\leq 25$ & 53 & 3.4712 & 0.8917 & 2.008 & 123 & 0.046 \\
\hline \multirow{5}{*}{$\begin{array}{l}\text { Table V. } \\
t \text {-tests for age differences } \\
\text { in attitudes towards } \\
\text { organizational creativity } \\
\text { barriers }\end{array}$} & & $>26$ & 72 & 3.2183 & 1.0322 & & & \\
\hline & Q15 & $\leq 25$ & 53 & 3.4808 & 0.9241 & -0.464 & 123 & 0.643 \\
\hline & & $>26$ & 72 & 3.5352 & 0.8965 & & & \\
\hline & Q17 & $\leq 25$ & 53 & 3.5385 & 0.6918 & 5.605 & 123 & 0.000 \\
\hline & & $>26$ & 72 & 2.8028 & 0.9545 & & & \\
\hline
\end{tabular}

ways of doing things. Our results would imply that employee teams should be allowed to decide how to achieve their goal; permitting such freedom and autonomy makes intrinsic motivations soar. Based on research studies of Arab managers and workplace environments, however, it is not at all clear whether this effect would occur in the high power distance of Arab culture. Another implication here is that rather than focusing on outcomes, managers should focus on how people are approaching the work and the strategies being used, provide coaching to overcome problems and clarify approach. Zuckerman (1997) found that successful scientists typically had mentors - more senior scientists - who not only imparted knowledge but also strategies and methods for approaching problems.

The students participated in this survey may not represent the population at large. Consequently, we do not extrapolate the findings to a particular population. It should be noted that the participants in this study were future managers in a graduate degree programme. Their interest in furthering their knowledge of business by attending a university programme may not be completely representative of all managers. However, future research with managers from other countries may test the generalisability of our findings across cultures. 


\section{References}

Abra, J. (1991), "Gender differences in creative achievement: a survey of explanations", Genetic, Social \& General Psychology Monographs, Vol. 117, pp. 235-85.

Abu-Faris, M. (1990), “Administrative innovation in public enterprises in Jordan”, Masters Thesis, University of Jordan, Amman, Jordan.

Abu-Taieh, S. (2003), "The relationship between leadership style and innovative behaviour: a field study on Jordanian managers working in large industrial firms", (in Arabic), Dirasat, Vol. 30, pp. 371-86.

Al-Beraidi, A. and Rickards, T. (2003), "Creative team climate in an international accounting office: an exploratory study in Saudi Arabia”, Managerial Auditing Journal, Vol. 18, pp. 7-18.

Ali, A. (1993), "Decision-making style, individualism, and attitudes towards risk of Arab executives”, International Studies of Management and Organization, Vol. 23, pp. 53-74.

Amabile, T. (1983), The Social Psychology of Creativity, Springer-Verlage, New York, NY.

Amabile, T. (1988), "A model of creativity and innovation in organizations", in Staw, B.M. and Cummings, L.L. (Eds), Research in Organizational Behavior, JAI Press, Greenwich, Connecticut, Vol. 10, pp. 123-67.

Amabile, T., Conti, R., Coon, H., Lazenby, J. and Herron, M. (1996), "Assessing the work environment for creativity”, Academy of Management Journal, Vol. 39, pp. 1154-84.

Awamleh, A. (1994), "Managerial innovation in the civil service in Jordan: a field study", Journal of Management Development, Vol. 13, pp. 52-60.

Barakat, H. (1993), The Arab World: Society, Culture and State, University of California Press, CA.

Barron, F. and Harrington, D. (1981), "Creativity, intelligence, and personality”, Annual Review of Psychology, Vol. 32, pp. 439-76.

Basadur, M., Federowicz, J. and Potworowski, J. (1988), Exploring Issues in the Management of Technology, McMaster University, Hamilton.

Basadur, M., Pringle, P. and Kirkland, D. (2002), "Crossing cultures: training effects on the divergent thinking attitudes of Spanish-speaking South American managers”, Creativity Research Journal, Vol. 14, pp. 395-408.

Block, J. (1976), "Issues, problems, and pitfalls in assessing sex differences: a critical review of the psychology of sex differences”, Merrill-Palmer Quarterly, Vol. 22, pp. 283-308.

Chakrabarti, A. (1974), "The role of champion in product innovation", California Management Review, Vol. 17, pp. 58-62.

Child, D. (1990), The Essentials of Factor Analysis, Casell, London.

Comrey, A. (1973), A First Course in Factor Analysis, Academic Press, New York, NY.

Csikszentmihalyi, M. (1996), Creativity, Flow and the Psychology of Discovery and Invention, Harper Collins, New York, NY.

Davis, G. (1989), “Testing for creative potential”, Contemporary Educational Psychology, Vol. 14, pp. 257-74.

Davis, G. and Rimm, S. (1989), "Group inventory for finding interests (GIFFI) 1 \& 2: instruments for identifying creative potential in junior and senior high school”, Journal of Creative Behavior, Vol. 16, pp. 50-7.

Dixon, J. (1993), "Grouping techniques”, in Munro, B.H., and Page, E.B., Statistical Methods for Health Care Research, 2nd ed., J.B. Lippincott Co., Philadelphia, PA.

Gatewood, R. and Field, H. (1990), Human Resource Selection, 2nd ed., The Dryden Press, Chicago, IL.
Perceived

barriers to organizational

creativity 
$\mathrm{CCM}$

15,1

92

George, D. and Mallery, P. (2000), SPSS for Windows: A Simple Guide and Reference, 2nd ed., Allyn and Bacon, Boston, MA.

Green, S., Salkind, N. and Akey, T. (2000), Using SPSS for Windows: Analyzing and Understanding Data, 2nd ed., Prentice-Hall, Upper saddle River, NJ.

Gundry, L. and Kickul, J. (1994), "Building the creative organization”, Organizational Dynamics, Vol. 22, pp. 22-37.

Hair, J., Anderson, R., Tatham, R., and Black, W. (1995), Multivariate Data Analysis, 4th ed., Prentice-Hall, Englewood Cliffs, NJ.

Hambrick, D. and Mason, P. (1984), "Upper echelons: the organization as a reflection of its top management", Academy of Management Journal, Vol. 15, pp. 514-35.

Herbig, P. and Jacobs, L. (1996), "Creative problem solving style in the USA and Japan", International Marketing Review, Vol. 13, pp. 63-71.

Hocevar, D. and Bachelor, P. (1989), Handbook of Creativity, Plenum Press, NJ.

Hofstede, G. (1980), Culture's Consequences: International Differences in Work-related Values, Sage, Beverly Hills, CA.

Howell, J. and Higgins, C. (1991), "Champions of change: identifying, understanding, and supporting champions of technological innovations", Organization Dynamics, Vol. 10, pp. 40-55.

Instone, D., Major, B. and Bunker, B. (1983), "Gender, self-confidence and social influence: an organizational simulation”, Journal of Personality and Social Psychology, Vol. 44, pp. 322-33.

Kaiser, H. (1970), “A second generation little jiffy”, Psychometrika, Vol. 35, pp. 401-15.

Kao, J. (1991), Managing Creativity, Prentice-Hall, Englewood Cliffs, NJ.

Kim, J. and Mueller, C. (1978), Introduction to Factor Analysis, Sage Publications, Beverly Hills, CA.

Klecka W. (1987), Discriminant Analysis, 8th ed., Sage, Beverly Hills, CA.

Lever, J. (1976), "Sex differences in games children play”, Social Problems, Vol. 23, pp. 478-87.

McGorr, S. (2000), "Measurement in a cross-cultural environment: survey translation issues", Qualitative Market Research, Vol. 3, pp. 74-81.

Makhamerah, M. and Al-Dahhan, O. (1988), "Factors affecting innovation in public industrial companies in Jordan", (in Arabic), Dirasat, Vol. 15, pp. 151-72.

Malhotra N. (2004), Marketing Research: An Applied Orientation, Prentice-Hall, Upper Saddle River, NJ.

Malinowski, B. (1935), Coral Gardens and Their Magic, 2: The Language of Magic and Gardening, George Allen \& Unwin, London.

Mikdashi, T. (1999), "Constitutive meaning and aspects of work environment affecting creativity in Lebanon", Participation and Empowerment: An International Journal, Vol. 7, pp. 47-55.

Mostafa, M. (2003), "Attitudes towards women who work in Egypt", Women in Management Review, Vol. 18, pp. 252-66.

Mostafa, M. (2005), "Factors affecting organizational creativity and innovativeness in Egyptian business organizations: an empirical investigation", Journal of Management Development, Vol. 24, pp. 7-33.

Mott, P. (1972), The Characteristics of Effective Organizations, Harper \& Row, NY.

Napahiet, J. and Ghoshal, S. (1998), "Social capital, intellectual capital and the organizational advantage", Academy of Management Review, Vol. 23, pp. 242-66.

Nasif, E., Al-Daeaj, H., Ebrahimi, B. and Thibodeaux, M. (1991), "Methodological problems in cross-cultural research: an updated review", Management International Review, Vol. 31, pp. 13-32. 
Nunally, J. (1978), Psychometric Theory, 2nd ed., McGraw-Hill, New York, NY.

Phillips, H. (1959), "Problems of translation and meaning in field work", Human Organization, Vol. 18, pp. 184-92.

Wong, C. and Pang, W. (2003), "Barriers to creativity in the hotel industry: perspectives of managers and supervisors", International Journal of Contemporary Hospitality Management, Vol. 15, pp. 29-37.

Woodman, P. and Schoenfeldt, L. (1989), "Individual differences in creativity: an interactionist perspective", in Glover, J.A. et al., (Eds), Handbook of Creativity, Plenum, New York, pp. 77-92.

\section{Further reading}

Zuckerman, H. (1978), "Theory choice and problem choice in science”, Sociological Inquiry, Vol. 48, pp. 65-95.

\section{Appendix. Barriers-to-creativity instrument ${ }^{\mathrm{a}}$}

Not feeling involved

Low morale

Lack of communication

Conflicting goals and objectives

Lack of peer cohesion and support

No recognition and appreciation of work done.

Risk aversion

Fear of failure

Threatening evaluation

Destructive criticism

Status quo ${ }^{\mathrm{b}}$

Management turn-down of suggestions

Not supported by the management

Time pressure

Work pressure

Rules and regulations to follow ${ }^{\mathrm{b}}$

Conservative management style

( Items are rated on a five-point scale: $\left(1=\right.$ strongly disagree; $5=$ strongly agree); ${ }^{\text {b }}$ items deleted from analysis.)

\section{Corresponding author}

Mohamed M. Mostafa can be contacted at:mostafa@usa.com

To purchase reprints of this article please e-mail: reprints@emeraldinsight.com Or visit our web site for further details: www.emeraldinsight.com/reprints 